\title{
Changes in Temporomandibular Joint Dysfunction Symptoms Following Massage Therapy: A Case Report
}

\author{
Melissa Joan Pierson, MT \\ Optimum Wellness Centres, Calgary, Alberta, Canada
}

Purpose: The objective of this case report was to describe the effects that massage therapy had on a woman with temporomandibular joint dysfunction.

Participant: The 26-year-old woman's primary symptoms were pain, decreased range of motion, clicking, and crepitus. These symptoms were reportedly associated with emotional stress and bruxism.

Intervention: Ten 45-minute massage therapy treatments were administered over a five-week period. The client's progress was monitored by an initial, midway, and final assessment, using range of motion testing, personal interview, an orthopedic test, and postural analysis. Progress was also evaluated by the use of a daily journal. The client participated in a home care routine consisting of stretches, self-massage, postural training, a proprioception exercise, and hydrotherapy.

Results: Results include an increase in maximal opening from $3.1 \mathrm{~cm}$ to $3.8 \mathrm{~cm}$, an overall increase in neck range of motion, a decrease in muscle hypertonicity using the Wendy Nickel's Scale, a decrease in pain from $7 / 10$ to $3 / 10$ on a numerical pain scale, and a decline in stress.

Conclusion: Although the client in this report experienced positive results, more extensive studies are needed to understand the effects of massage on TMD.

KEYWORDS: temporomandibular joint; intraoral; TMD; stress; jaw pain; bruxism

\section{INTRODUCTION}

\section{Temporomandibular Joint Dysfunction (TMD)}

Researchers have estimated that $65 \%-85 \%$ of Americans experience some symptoms of temporomandibular joint dysfunction (TMD) during their lives ${ }^{(1)}$. This is perhaps owing to the fact that the temporomandibular joint (TMJ) is the most frequently used joint in the body, moving 2000-3000 times a day $^{(2)}$. TMD is a condition that encompasses several pathologies of the jaw and the muscles of mastication (chewing) ${ }^{(3)}$. Symptoms of TMD are most common in people between 15 and 45 years of age, and are more common in women than men by a ratio of $5: 1^{(4)}$. A triad of predisposition, tissue alteration (neuromuscular, skeletal, and dental), and stress sufficient to cause jaw clenching and/or bruxism is usually necessary to provoke $\mathrm{TMD}^{(4)}$

Symptoms of TMD vary from case to case, but common complaints include: spasm and/or pain in the head, jaw, neck, and shoulder muscles; headaches; earaches; jaw clicking or deviation; limited jaw opening; clenching or grinding of the teeth; and dizziness ${ }^{(3,5)}$. Causes can include whiplash, bruxism, malocclusion, anxiety, stress, trigger points, and postural dysfunction ${ }^{(3,6)}$.

It is important for patients to seek treatment because muscle contractures may develop and degeneration of the disc, condylar head and articular eminence may occur if not corrected ${ }^{(4)}$. There are several approaches to the treatment of TMD. These treatment strategies are as diverse as the patients presenting the symptoms. Because each patient presents differently, he or she should be assessed and treated according to his or her distinct needs. Because most of the causes and conditions associated with TMD are irremediable, it has been suggested that treatment be aimed toward symptomatic relief and not cures ${ }^{(1)}$. Common treatment options include: splint therapy, occlusal adjustment, analgesic medications, surgery, acupuncture, trigger point injections, hydrotherapy, therapeutic ultrasound, electromyopathy, hypnorelaxation, cognitive-behavioral therapy, massage therapy, stress management, and biofeedback ${ }^{(3,7)}$. Home care practices such as a soft food diet, a local application of ice, self-massage, hot showers, and stretching have also been suggested as being beneficial $^{(3,4,7)}$.

Treatments that are discussed in the dentistry literature focus on surgical repair, splint therapy, and medication ${ }^{(7-10)}$. In addition, some dentists may choose to refer their patients to massage therapists to assist in treatment of this condition. Although support for the use of massage therapy as a part of a comprehensive treatment solution for TMD has been discussed $^{(11)}$, literature that addresses the effectiveness of massage therapy on TMD is limited and studies report varying degrees of success ${ }^{(11-16)}$. 


\section{Massage and TMD}

When participants of a focus group consisting of 85 people diagnosed with TMD were asked what the primary motivation would be for joining a complementary and alternative medicine (CAM) trial on TMD, answers included reducing the use of pain medication, decreasing dental visits, stabilizing the condition, and reducing the self-care burden ${ }^{(17)}$. Participants expressed general frustration with conventional care for TMD, and some had used massage therapy and found it helpful. In addition, a survey of 192 patients with TMD was conducted by DeBar et al. ${ }^{(18)}$ to assess patients' use, satisfaction with, and perceived effectiveness of a variety of CAM therapies for specific health conditions. Nearly two-thirds of the participants reported using CAM for TMD or a related condition. Of the 69 patients who used CAM for TMD, massage was most commonly used (66.7\%), while chiropractic care, herbal supplements, and homeopathic remedies were reported as being used less frequently (39.1\% or less). Massage was reported as the most satisfactory CAM therapy for TMD, with $60.9 \%$ of respondents "very" or "extremely satisfied". It is also interesting to note that the vast majority (95.6\%) reported using CAM and conventional care together to address their TMD.

While it is generally accepted that massage therapy is a relatively safe treatment ${ }^{(19)}$, some modifications for TMD treatment may be necessary. Vinyl medical gloves are used for intra-oral massage instead of latex if a latex allergy is present, heavy pressure is avoided when working intra-orally, and techniques that compress the mandible superiorly against the TMJ are avoided $^{(4)}$. These modifications to the administration of massage intervention were considered throughout the treatment series.

\section{Massage and Stress}

As previously noted, massage therapy has been suggested as a noninvasive treatment option for TMD. One of the unique abilities of massage therapy is the potential to concurrently address the mechanical, the neurological, and the emotional symptoms in a personalized, holistic manner. Many stress-related conditions such as depression, chronic pain, posttraumatic stress disorder, and job anxiety have been positively affected by massage therapy, with changes in mood noted immediately after treatment ${ }^{(20-23)}$. Effects on cortisol, serotonin, and dopamine have been proposed as mechanisms for these changes, but are currently being debated in the literature $(20,21,24,25)$. According to Jerjes et. al. ${ }^{(3)}$, TMD can create a cycle where stress causes bruxism, which causes pain, and that pain then affects the quality of life, causing more stress; therefore, the possible stress-reducing benefits of massage are of particular interest.

\section{Case Report Objective}

The lack of articles supporting massage for TMD calls for further exploration of the effectiveness of massage techniques on jaw pain. The objective of this case report is to describe changes in TMD symptoms in a client following 10 sessions of massage therapy and a home care regime. This case report is important to the health field because it reports on the value of coupling a treatment plan with detailed measurements of relevant signs and symptoms.

\section{PARTICIPANTS}

\section{Profile of Client}

This report involves a 26-year old, female student with TMD that began idiopathically seven to ten years prior to the massage treatment series. Her primary symptoms were pain, decreased range of motion, clicking, and crepitus. She believed these symptoms were related to emotional stress and bruxism. Her activities of daily living included going to school eight hours a day/five days a week, studying for an hour or two each evening, watching TV or a movie approximately every other day, and weekend road trips about once a month. She did not work on a computer at school, but was required to take a good deal of notes by hand and is right-side dominant. Some diet choices such as chewing gum, sucking straws, and eating hard foods increased the client's pain, so she avoided these and abided by a soft foods diet. When pain symptoms were severe she took Tylenol; to decrease stress she would smoke cigarettes. Treatment for TMD was sought from a dentist and a TMJ specialist, the latter being the professional who diagnosed her with TMD two years prior to her first massage therapy appointment. The repeated action of grinding her teeth at night and clenching during the day was causing damage to her teeth as relayed to the client by her dentist, who said they appeared to have ten extra years of "wear and tear". Her dentist fit her with a maxillary bruxism splint appliance that she was instructed to wear at night; however, she chose not to wear it on a regular basis due to alleged discomfort and subsequent loss of sleep. Treatment with the TMJ specialist consisted of diet changes, stretching, and other home care, and guidance on decreasing stress. The client saw a decrease in the majority of her symptoms and she reported that her teeth became healthier due to less jaw grinding; however, when this specialist moved, treatment ceased. Due to the home care style of treatment, when the sessions ceased, the client's symptoms remained "relatively stable". Nevertheless, when her stress increased, the symptoms returned. The client's long-term goal for the massage therapy treatment series was to decrease her pain, with short-term goals including decreasing 
muscle tension and restrictions in the neck and facial muscles, and decreasing stress.

\section{INTERVENTION - TREATMENT PLAN}

\section{Treatment Overview}

The massage therapy intervention series consisted of an initial assessment followed by five treatments, re-assessment, five additional treatments, and a final assessment. Treatment was scheduled to occur twice a week as recommended by Rattray \& Ludwig( ${ }^{(4)}$; however, that was altered once because the client was exceptionally stressed and did not feel up to having a treatment that day, and another time as a consequence of the client forgetting that treatment was scheduled for that day. Despite this, treatment never exceeded three times a week, and was never more than seven days apart.

\section{Massage Intervention}

The massage therapy intervention remained fairly consistent, with slight changes being made during each massage according to the needs of the client. For example, due to the scheduling conflicts mentioned above, there was one week where massage was scheduled on Monday, Wednesday, and Friday. Due to this higher frequency of treatment, the client and the massage therapist felt that it might be too overwhelming for the client to receive intra-oral massage each of these days. Therefore, the mid-week treatment excluded work inside the mouth and instead focused on myofascial release to the neck and chest, and traditional Swedish techniques to the neck. During each treatment session, the client was massaged for 45-50 minutes around noon in a dimly lit room with no music. She was positioned supine on the massage table, draped with linens and a warm blanket, with pillows propped under her knees to reduce strain on her back. [See Table 1 for an outline of the treatment plan.]

The treatment began with effleurage, using the 2 nd and 3rd fingers in a circular direction over the masseter muscles to encourage the muscles to relax before intra-oral massage. After this, intra-oral massage was conducted as described by Rattray \& Ludwig( ${ }^{(4)}$ and Judith DeLany ${ }^{(26)}$. Using one gloved finger, the masseter was located inferior to the zygomatic arch with the finger pad facing the cheek. Pressure was applied with the thumb on the outside of the cheek, creating a pincer-like compression. Placing the finger on the last lower molar, the medial pterygoid was then accessed by sliding the finger medially and posteriorly. Finally, to locate the lateral pterygoid, the finger was placed between the upper last molars and the cheek, while pressure was applied in a superior and posterior direction. Each muscle of mastication was compressed for approximately eight seconds and released for approximately two seconds. This was repeated five times on average per muscle to release trigger points and muscle tension. Gentle muscle stripping was also performed to these same muscles. At the beginning

TABle 1. General Treatment Plan Outline

\begin{tabular}{|c|c|c|c|}
\hline Area & Technique & Muscles & Other \\
\hline $\begin{array}{l}\text { Warm-up } \\
1 \text { minute }\end{array}$ & $\begin{array}{l}\text { Small finger circles and gentle } \\
\text { muscle stripping }\end{array}$ & Masseter & \\
\hline $\begin{array}{l}\text { Intra-oral } \\
10 \text { minutes }\end{array}$ & $\begin{array}{l}\text { Compress/release ( } 8: 2 \text { seconds) } \sim 5 \mathrm{X} \text { per } \\
\text { muscle, light muscle stripping }\end{array}$ & $\begin{array}{l}\text { Masseter, medial and } \\
\text { lateral pterygoids }\end{array}$ & $\begin{array}{l}\text { Client can communicate via } \\
\text { holding therapist's arm } \\
\text { Non-latex gloves used }\end{array}$ \\
\hline $\begin{array}{l}\text { Myofascial } \\
20 \text { minutes }\end{array}$ & $\begin{array}{l}\text { Extra muscular technique to neck ( } 4 \text { loca- } \\
\text { tions - lateral [over upper traps], anterior } \\
\text { [over scalenes], anterior [over SCM] \& } \\
\text { posterior [over erector spinae] } 3-5 X \text { each. } \\
\sim 15 \text { sec each. Pec release, hyoid release, } \\
\text { and intramuscular technique to SCM }\end{array}$ & $\begin{array}{l}\text { Fascial work surrounding scalenes, } \\
\text { SCM, cervical erector spinae, } \\
\text { splenius capitus, platysma, pec } \\
\text { major, hyoids, upper traps }\end{array}$ & No lotion used \\
\hline $\begin{array}{l}\text { Neck } \\
10 \text { minutes }\end{array}$ & $\begin{array}{l}\text { Kneading, stripping, finger circles, trigger } \\
\text { point release, and occipital traction }\end{array}$ & $\begin{array}{l}\text { Upper traps, scalenes, pec major, } \\
\text { platysma, cervical erectors, } \\
\text { splenius capitus, suboccipitals, } \\
\text { and levator scapulae }\end{array}$ & \\
\hline $\begin{array}{l}\text { Face/Head } \\
3 \text { minutes }\end{array}$ & $\begin{array}{l}\text { Scalp shiatsu, light stripping frontalis, } \\
\text { trace eyebrows, eyebrow pressure pts, } \\
\text { trace under zygomatic arch \& mandible, } \\
\text { finger circles temporalis \& masseter }\end{array}$ & $\begin{array}{l}\text { Frontalis, temporalis, hyoids, } \\
\text { masseter, all facial muscles \& } \\
\text { galea aponeurotica }\end{array}$ & $\begin{array}{l}\text { Diaphragmatic breathing coached, } \\
1 \text { drop lavender essential oil with } \\
\text { massage lotion }\end{array}$ \\
\hline $\begin{array}{l}\text { Strip/Stretch } \\
2 \text { minutes }\end{array}$ & $\begin{array}{l}5 \mathrm{X} \text { each masseter and temporalis, } \\
\text { compress/stretch } 5 \mathrm{X} \text { masseter }\end{array}$ & Masseter and temporalis & $\begin{array}{l}\text { Client passively opens mouth while } \\
\text { therapist strips superiorly } \\
\text { Small amount lotion }\end{array}$ \\
\hline
\end{tabular}


PIERSON: CHANGES IN TEMPOROMANDIBULAR JOINT DYSFUNCTION SYMPTOMS

of the treatment series, light pressure was used intraorally; as the client became more accustomed to the technique, the pressure increased to moderate. Even though caution with pressure was used, intra-oral massage was slightly uncomfortable for the client and made her "tense up"; therefore, she preferred to have it done near the beginning so she could focus on relaxing for the rest of the treatment.

Myofascial massage was then performed to the neck and chest. Extramuscular techniques were used at four locations on the neck: laterally over the upper trapezius, anteriorly over the scalenes, anteriorly over the sternocleidomastoid (SCM), and posteriorly over the cervical erector spinae muscles. Three to five releases were performed in each location by holding the area with one hand and stretching the head in the opposite direction with the other. When the tissue softened, it was followed with a stretch in the direction of the barrier and held for approximately 15 seconds. The pectoralis major muscle and surrounding fascia were also treated in a similar fashion - the tissue was compressed with the fingers while the arm was passively taken into flexion and abduction. If a significant softening was not felt this way, pectoralis major was then grasped on the lateral edge with the fingers on top and thumb in the axilla, and the arm was taken into flexion and abduction. Intramuscular technique was used on SCM by picking up and twisting the muscle to release trigger points and tension.

The rationale for choosing to implement myofascial release was that, according to Warren Hammer, DC, MS, "fascia transmits tension and may be responsible for decreased ranges of motion and pain ${ }^{(27) "}$. Also, jaw pain frequently affects the cervical area ${ }^{(11)}$ or vice versa through the secondary factor of faulty posture. For example, rounded shoulders cause a person to abnormally extend the neck, which places excessive force on the jaw ${ }^{(11)}$. Therefore, the author's rationale for accessing the fascia surrounding the chest was to correct the rounded shoulder posture, which would, in turn, release the pressure on the jaw. Also, it was suspected that the anterior neck fascia was shortened due to the client feeling like she had to cough when actively extending the neck and the presence of forward head posture. This tension was presumed to be pulling on the mandible; therefore, it was suspected that releasing anterior neck fascia would decrease symptoms of TMD. No massage lotion was used during this part of the massage in order to obtain proper tension on the fascial system; therefore, it was important to have this segment precede Swedish massage, which uses lotion.

Swedish massage techniques, such as kneading, muscle stripping, finger circles, and trigger point release through ischemic compression were used on the neck muscles. These techniques-particularly trigger point release-have been suggested to relieve pain, increase blood flow to the muscles, and elevate endorphin levels ${ }^{(7)}$. These three outcomes are important because they coincide with the client's goals for treatment to decrease her pain and stress. Increasing blood flow to the area may increase the oxygen and nutrition to tissue cells, assisting them in their proper function ${ }^{(4)}$. Several trigger points refer to the jaw/head such as upper trapezius to the angle of the mandible, the sternal division of SCM to the zygomatic arch, and platysma to the mandible(28); therefore, releasing trigger points in this area may decrease pain felt in the jaw.

Aromatherapy was implemented during the head/ face portion of treatment by using one drop of lavender essential oil mixed with one teaspoon of massage lotion. Although no direct references to the use of aromatherapy for TMD were found, there are some references to its usefulness in treating stress and anxiety ${ }^{(29,30)}$. Lavender was selected for its relaxing and calming benefits ${ }^{(31,32)}$. The client was coached on using diaphragmatic breathing during the head and face massage to promote relaxation by decreasing the effects of the sympathetic nervous system ${ }^{(4,33)}$. Scalp shiatsu was performed with an intent to restore and maintain the body's energy balance, prevent the buildup of stress, and decrease pain ${ }^{(34)}$. Shiatsu is an oriental medicine technique using gentle manipulations and stretches combined with pressure techniques through the fingers and thumbs. The points used were six points from the hairline towards the back of the head in equal distances, each point being held for three seconds and repeated three times. Using these six points as a guide and moving laterally for two additional rows on the left and two on the right, a total of thirty points were compressed with the thumbs.

The treatment concluded with the masseter, the same muscle it began with, to bring a sense of completion to the massage and to focus on the main area of pain. It was compressed bilaterally and stripped superiorly, while the client opened her jaw to a count of three. This was repeated approximately five times. This method was also repeated on the temporalis muscles.

\section{Home Care}

Studies have shown that $60 \%-90 \%$ of patients with TMD report an improvement in symptoms after using only self-management ${ }^{(7)}$; therefore, self-care was an integral part of the treatment plan. The client was given a home care sheet on the first day of the treatment series with instructions for exercises that she was to perform daily.

An exercise called "cervical retraction to decrease forward head posture" as explained by Kisner and Colby ${ }^{(35)}$ was performed by lightly touching above the lip under the nose and lifting the head up and away by tucking in the chin and straightening the spine. The client moves into the extreme of the correct posture and then returns to midline. She was instructed to perform this throughout the day as needed (at least 
three times). This exercise was important because poor posture can place excessive force on the jaw ${ }^{(11)}$ and postural training has been found to increase maximal jaw opening ${ }^{(2)}$.

To actively find relief throughout the day, the client performed a compress and stretch exercise to masseter and temporalis by compressing the muscle belly while slowly opening the mouth. She was also instructed to perform this throughout the day as needed (at least five minutes total each day). Wright \& Schiffman ${ }^{(7)}$ suggest that patients instructed in self-massage are able to maintain more permanent comfort because they have an effective treatment at their disposal. The subject chose to not use Tylenol or wear her splint over the course of the treatment series.

The home care sheet was updated after the midway assessment, and a proprioception exercise involving resting the jaw muscles was added, as well as vascular flush hydrotherapy, both of which are outlined in a handout used at the TMD Clinic, Lackland Air Force Base, Texas ${ }^{(7)}$.

The proprioception exercise was explained to the client as follows: "Keep your teeth apart and practice good posture. When you're not chewing, your teeth should never touch (except occasionally when you swallow). Closely monitor your jaw position for signs of clenching. Try placing your tongue lightly on the top of your mouth behind your upper front teeth, allowing the teeth to come apart and relaxing the jaw muscles ${ }^{(7)}$." This was implemented to try to break the habit of clenching the jaw, indicated in part by the client saying, "My jaw likes to be closed."

The hydrotherapy was introduced to increase local circulation by alternating vasodilation and vasoconstriction of the arterioles and capillaries ${ }^{(4)}$. Vascular flush (also called contrast treatment) was chosen over heat only or cold only, because although the client's TMD was chronic (indicating heat treatment), aggravating factors like clenching and grinding may have caused inflammation (indicating cold treatment). Therefore, the combination of both therapies seemed most appropriate. The client was instructed to apply moist heat for ten minutes to the painful area with a towel that was run under hot tap water, then lightly brush the area with an ice cube, wrapped in a thin washcloth, until some numbness was felt. She was asked to repeat this sequence three times, ending with cold.

Also, after pectoralis major myofascial massage was implemented midway into the treatment series, the client expressed interest in repeating this on her own because she found it to be effective. She was encouraged to do so.

Recommendations were given to the client, following the final assessment, to continue the home care exercises, the use of lavender essential oil and massage treatments. She was advised to decrease emotional stress and any other self-identified triggers that increase her symptoms of TMD.

\section{INTERVENTION - TREATMENT PLAN: MEASUREMENT}

\section{Assessment Overview}

Progress was recorded by an initial assessment prior to the first massage treatment, re-assessment between the fifth and sixth treatments, and a final assessment after the tenth treatment. Each assessment included a personal interview, postural assessment, measures of active, passive, and resisted ranges of motion for the neck and TMJ, and one orthopedic test. Muscle tension was monitored each treatment through palpation. To track daily activities and symptoms, a journal was completed by the client. These measurements were chosen to evaluate symptoms both objectively and subjectively. Combining both types of data is a common and effective way to monitor and evaluate progress ${ }^{(11,15)}$.

\section{Personal Interview}

During the personal interview, the author asked the client questions regarding the onset of symptoms, location of discomfort, pain referral pattern, duration and frequency of pain, intensity and quality of pain, interference with activities of daily living, aggravating and relieving factors, and related symptoms.

\section{Postural Assessment}

Postural distortion was analyzed by visual observation as described by Magee ${ }^{(36)}$ using a plumb line and rated as either mild, moderate, or severe. The plumb line consisted of a weight hanging on a string suspended in a doorframe to provide a gravitational reference. The client stood on one side of the string while the author stood on the other and recorded any visible deviations. Lateral, posterior, and anterior views were observed.

\section{Range of Motion Assessment}

The neck and TMJ were assessed using active, passive, and resisted ROM with degrees of movement and muscle strength estimated by the author. Results obtained were compared with normal ROM degrees from Magee's orthopedic physical assessment ${ }^{(36)}$. Neck ranges of motion measured were flexion, extension, lateral flexion, and rotation. TMJ ranges of motion measured were depression, elevation, lateral deviation, retraction, and protraction. Due to the degrees of motion of the TMJ being minute in comparison to the other joints of the body, rather than estimating degrees, each motion was graded as either normal or restricted. Other observations made and reported during TMJ ROM included pain or discomfort, joint sounds, and deviations. Resisted ROM for neck and TMJ 
was rated as either weak, normal, or stronger than normal. To more precisely measure TMJ depression, maximal opening was measured from the top teeth to the bottom teeth using a ruler, as described by two studies ${ }^{(1,15)}$. According to Gottlieb and Lautar ${ }^{(11)}$, this measurement is considered limited if it is under $3.5 \mathrm{~cm}$.

\section{Orthopedic Assessment}

Rattray and Ludwig's orthopedic test, the 'Three Knuckle Test'(4), was performed. It instructs the client to open the jaw and insert as many of his/ her flexed proximal interphalangeal joints of the nondominant hand between the teeth as possible. A positive test for TMJ hypomobility is indicated if the client can fit only one knuckle or no knuckles at all between the teeth. This test has been explained in published articles and textbooks as a way to measure $\operatorname{TMD}^{(4,11,28,36,37)}$. However, it has also been described as a simple "crude measurement"(37) of maximal opening and therefore, to the author's knowledge, its use is not routinely administered and universally accepted. A better quantifiable assessment would be the aforementioned ruler measurement.

\section{Palpation}

During each treatment, the Wendy Nickel's Scale (WNS) $)^{(38)}$ was used to rate the tension palpated by the therapist on a scale from -1 to $5,-1$ being lacking in tone and 5 being extremely severe tension.

\section{Daily Journal}

The client's progress was recorded through a daily journal that she filled out every evening, three weeks prior to the treatment series, to provide a clear picture of her symptoms, as well as to have a baseline "control". This journal was continued daily throughout the treatment series. Questions on the journal sheet included: stress level from one to ten; the suspected cause of stress; the number of tests in school; the location, referral pattern, quality, and duration of pain; the intensity of pain from one to ten; less, normal, or more joint clicking and popping (the client circles one); minimal, moderate, or severe clenching/grinding (the client circles one); amount and quality of sleep; home-care performed; other activities such as homework, TV, or computer; number of cigarettes smoked (removed from the sheet when she quit); and food consumed. Numbering stress from one to ten provided the report with a quantifiable measurement of subjective stress. Also, writing the suspected cause helped the author see if it could be eliminated throughout the treatment series, thereby reducing TMD symptoms. The reason the number of tests was tracked was to discern if they increased the amount of stress or pain. The location, referral pattern, quality, and duration of pain were recorded to see if they changed at all during the treatment series. The intensity of pain from one to ten was recorded for the same reason as stress, to provide the report with a quantifiable measurement. Clicking/popping and amount of clenching/grinding were evaluated to note any association with other symptoms. Sleeping duration and quality were evaluated to see if poor habits increased symptoms of TMD. Home care performed was recorded primarily as a means of accountability; the client may have felt more compelled to complete it if she knew she had to write it down. The author requested the client to record "other activities" to provide insight into daily habits. Food consumed was part of the journal, to assess the impact of crunchy tough foods on jaw pain and observe diet habits.

\section{RESULTS}

\section{Personal Interview}

At the initial assessment, the client described her pain as an achy, tired feeling in front of her ears, throughout the temples, occipital region, directly in the TMJ and sometimes down her neck and shoulders. To the client, this pain felt like a headache. She expressed that when her pain was at its peak, she did not want to talk or even turn her neck. When pain levels were low, an achy uncomfortable sensation still remained. The symptoms interfered with her daily living by decreasing concentration and patience.

Following the treatment series, self-reported pain decreased from $7 / 10$ to $3 / 10$ (see Table 2).

At the final assessment, the client remarked that her activities of daily living were no longer affected to the same extent, "just my concentration if the pain gets bad". She also noted that the achy uncomfortable sensation that was consistent prior to the treatment series, regardless of pain levels, "now comes and goes". Other comments on effectiveness of the treatment series overall were, "I feel a lot better", "treatment went really well", and "my jaw feels better".

\section{Postural Assessment}

At the initial and midway assessments, forward head posture and anterior rounding of the shoulders were rated as moderate, and at the final assessment, both were rated as mild. Initially, the client's right

TABLE 2. Pain Intensity

\begin{tabular}{cccc}
\hline Pain & $\begin{array}{c}\text { 1st } \\
\text { Assessment }\end{array}$ & $\begin{array}{c}\text { 2nd } \\
\text { Assessment }\end{array}$ & $\begin{array}{c}3 r d \\
\text { Assessment }\end{array}$ \\
\hline Intensity (1-10) & 7 & 5 & 3 \\
\hline
\end{tabular}


shoulder appeared approximately $2 \mathrm{~cm}$ higher than the left. By the mid-way assessment, the shoulders appeared to be of a more equal height and remained so at the final assessment.

\section{Range of Motion Assessment}

Maximal TMJ depression was evaluated during assessments and an increase was noted during each measurement (see Table 3). At the initial assessment, active ROM of the TMJ revealed that in depression, the jaw deviated to the left and clicked on the left side and the movement was restricted. During active elevation of the jaw, deviation was noted to the right. During active bilateral lateral deviation, crepitus (a grinding or grating sound) was noted on the right side. Passive ROM of TMJ depression was slightly greater than active, and remained so until the final assessment. Resisted ROM of TMJ depression and lateral deviation were uncomfortable. Resisted elevation was stronger than normal. All other TMJ ROM findings were normal and remained so until the final assessment. At the mid-way assessment, active ROM of TMJ depression remained the same. During active elevation, no deviation was noted and remained so until the final assessment. During lateral deviation, no crepitus was noted and remained so until the final assessment. Resisted ROM of depression was uncomfortable and lateral deviation was normal. Resisted elevation was stronger than normal. At the final assessment, active ROM of TMJ depression was no longer restricted but revealed a slight deviation to the left, then the right, then vertical. The click on the left side remained. Resisted ROM of all TMJ motions was normal.

Active ROM of the neck is shown to increase over time (see Table 3). At the initial assessment, the client felt bilateral "crackling" in the TMJ during active rotation to either side. This resolved by the mid-way

TABle 3. Active Range of Motion

\begin{tabular}{lcccc}
\hline \multicolumn{1}{c}{ Movement } & $\begin{array}{c}1^{\text {st }} \\
\text { Assessment }\end{array}$ & $\begin{array}{c}2^{\text {nd }} \\
\text { Assessment }\end{array}$ & $\begin{array}{c}3^{\text {rd }} \\
\text { Assessment }\end{array}$ & $\begin{array}{c}\text { Magnitude } \\
\text { of Change }\end{array}$ \\
\hline $\begin{array}{l}\text { TMJ (cm) } \\
\text { Depression }\end{array}$ & 3.1 & 3.7 & 3.8 & 0.7 \\
Neck (degrees) & & & & \\
$\quad$ Flexion & 45 & 60 & 60 & 15 \\
$\begin{array}{l}\text { Extension } \\
\text { Lateral }\end{array}$ & 20 & 50 & 70 & 50 \\
$\begin{array}{l}\text { flexion (R) } \\
\text { Lateral }\end{array}$ & 25 & 40 & 50 & 25 \\
$\begin{array}{l}\text { flexion (L) } \\
\text { Rotation }\end{array}$ & 70 & 45 & 55 & 25 \\
(R \& L) & 70 & 75 & 80 & 10 \\
\hline
\end{tabular}

assessment. Passive ROM of the neck was around 5 degrees greater for each motion than active ROM at the initial, mid-way, and final assessments, and therefore also increased over time. Resisted ROM of the neck at the initial assessment showed weakness in extension, flexion, and bilateral lateral flexion. At the mid-way assessment, these weaknesses remained, with the exception of flexion. At the final assessment, only extension was found to be weak.

\section{Orthopedic Assessment}

At the initial assessment, during the 'Three Knuckle Test', the client could fit two knuckles in with no extra room; therefore, this test was negative, but did provide a measurement to monitor progress. The results improved to $2 \frac{1}{2}$ knuckles at the mid-way assessment and $2 \frac{3}{4}$ at the final assessment.

\section{Palpation}

Using the WNS, hypertonicity was evaluated by the massage therapist in the muscles of mastication. Tension was observed to decrease throughout the treatment series (see Table 4).

\section{Daily Journal}

Upon examining the client's daily journal, correlations are noted between stress and pain, as noted in Figure 1. The way in which treatment days and weekends corresponded with stress and pain is also noted. Stress is shown to decrease from $9 / 10$ at the first journal entry to $5 / 10$ at the last. While observing stress on each treatment day and the following day, it is seen to decrease seven times and remain consistent two times. Pain observed in the same manner is seen to decrease four times, remain consistent two times and increase three times.

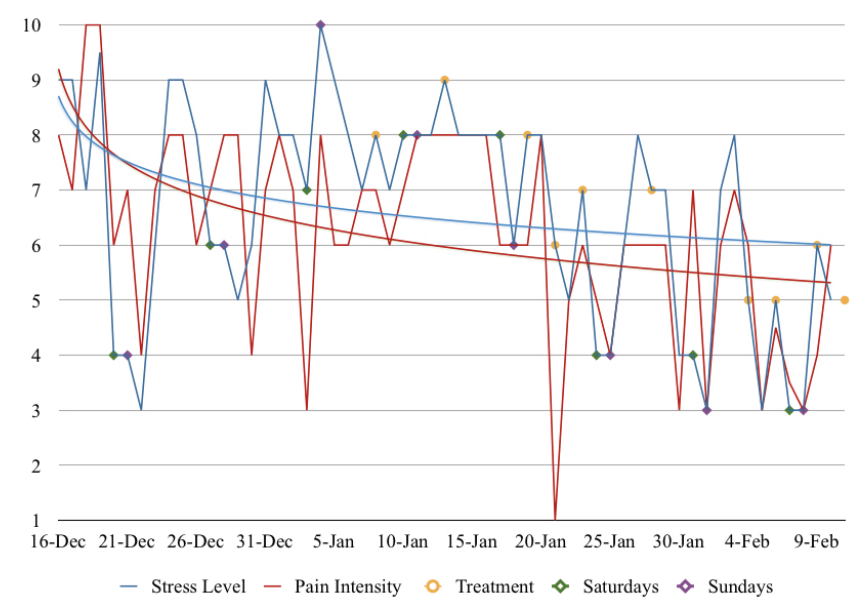

FIGURE 1. Correlation between stress levels and pain intensity in relation to weekends and massage treatments. 
TABLE 4. Hypertonicity Changes in the Muscles of Mastication*

\begin{tabular}{|c|c|c|c|c|c|c|c|c|c|c|}
\hline Hypertonicity & Jan 8 & Jan 13 & Jan 19 & Jan 23 & Jan 28 & $\mathrm{Feb} 4$ & $\mathrm{Feb} 6$ & Feb 9 & Feb 11 & $\begin{array}{l}\text { Magnitude } \\
\text { of Change }\end{array}$ \\
\hline \multicolumn{11}{|l|}{ Masseter } \\
\hline Left & 5 & 5 & 4.5 & 4 & 3 & 3 & 3.5 & 3.5 & 3.5 & 1.5 \\
\hline Right & 4 & 4 & 4 & 3 & 2.5 & 2.5 & 2.5 & 2.5 & 2.5 & 1.5 \\
\hline \multicolumn{11}{|l|}{ Lateral Pterygoid } \\
\hline Left & 4 & 3.5 & 4.5 & 4 & 4 & 3.5 & 3.5 & 3 & 2 & 2 \\
\hline Right & 4 & 3.5 & 3.5 & 3.5 & 3 & 3 & 2.5 & 2.5 & 2 & 2 \\
\hline \multicolumn{11}{|l|}{ Medial Pterygoid } \\
\hline Left & 4 & 4 & 3.5 & 3 & 3.5 & 3.5 & 3 & 3 & 2 & 2 \\
\hline Right & 4 & 4 & 3.5 & 3 & 3 & 3 & 3 & 3 & 2 & 2 \\
\hline
\end{tabular}

* Wendy Nickel's Scale: -1 [lacking tone] to 5 [severe tension]

Data gathered from the daily journals also shows occurrences of "severe" grinding/clenching, "more than normal" joint clicking/popping, and severe pain ( $8 / 10$ or higher) per week. The four weeks following the onset of the treatment series shows an overall decrease in occurrence for all three variables (Figure 2).

\section{DISCUSSION}

\section{Stress and Pain}

Although the limitations of a single case study are acknowledged, there still exists the opportunity to summarize and discuss findings regarding the changes noted postmassage therapy treatment. Throughout the course of the treatment series it was noted that emotional and mental stress correlated with the amount of pain the client was experiencing. A study regarding the effects of massage therapy on chronic pain ${ }^{(23)}$ found the same result and, in addition, stated that the authors were unable to discriminate whether massage techniques affected the perception of pain, thereby reducing stress, or vice versa. Referring to Figure 1, one can observe the parallel relationship

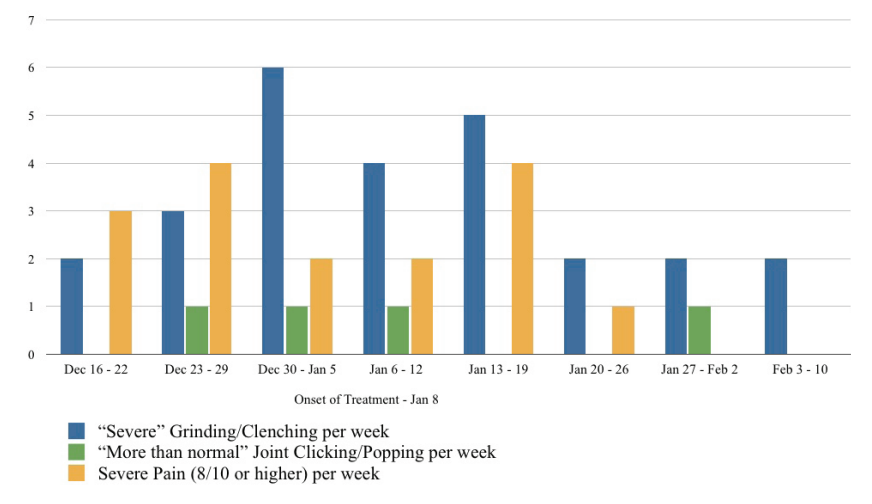

FIGURE 2. Occurrence of "severe" grinding/clenching, "more than normal" joint clicking/popping, and "severe" pain per week. between stress levels and pain intensity. Therefore, it appears when stress levels decrease, symptoms of TMD decrease, and vice versa. Two factors appear to influence stress and pain: weekends and massage treatment. Weekends are noted as less stressful than weekdays and when massage treatments were administered, pain and stress levels often dropped the following day. This finding coincides with the results found by Kemper and Shannon ${ }^{(20)}$ that massage reduces anxiety, and the suggestion by Wright and Schiffman ${ }^{(7)}$ that massage can be responsible for pain relief and relaxation. The observations regarding weekends versus weekdays may indicate that the major cause of the client's symptoms was events at school, and since withdrawing from school was not an option for her, massage therapy during the week was a good way to separate herself from the stresses of daily life.

\section{Joint Sounds}

Joint sounds were found to decrease only slightly (see Figure 2) and the click in the left TMJ remained after the treatment series. This finding is in agreement with a study claiming that joint sounds may remain unchanged despite other apparent improvements after TMD treatment ${ }^{(3)}$. Although the cause of unchanged joint sounds in this case is unknown, some possibilities are lateral pterygoid incoordination, an abnormally shaped disc, or disc degeneration ${ }^{(4)}$.

\section{Range of Motion}

One of the most substantial changes was the improvement in range of motion, especially maximal TMJ depression (see Table 3). This increase in 0.7 $\mathrm{cm}$ may have been due to any aspect of the treatments, home care, or lifestyle choices. According to a systematic review ${ }^{(16)}$, active exercise, manual therapy, postural training, and relaxation techniques, may decrease pain and increase total vertical opening (maximal TMJ depression). 


\section{Effectiveness of Treatment}

Overall, the treatment series was found to be successful, with positive changes noted by both the client and the author. This could be attributed to several factors, including: patient compliance, using evidence-based techniques, and frequent treatment with no prolonged breaks between sessions. The massage techniques and home care that seemed most effective in the opinion of the client were: the strip and stretch segment, intra-oral massage, self-myofascial release to pectoralis major, and the compress and stretch home care to masseter and temporalis. It is the author's opinion that direct techniques to the muscles of mastication through intra-oral massage may have had the biggest impact on maximal TMJ depression, considering that hypertonic shortened mandible elevators (masseter, lateral pterygoid, and medial pterygoid) limit TMJ depression. Therefore, specific work to decrease tension in these muscles would hypothetically allow for greater range of motion. Trigger point release also appeared to have a positive effect. During the last treatment, while releasing a trigger point through ischemic compression to the left oblique capitus superior, the client reported, "the pain is less and it decreases much faster than the first few treatments."

One aspect of the treatment series found to be ineffective to the client was the stretch given to release tension in the muscles of mastication by opening the mouth with the fingers and deviating the jaw to each side. This stretch was found to be uncomfortable for the client and was therefore removed after the midway assessment.

\section{Measurement Tools}

For greater accuracy in measurement, the author acknowledges that additional resources could have been utilized, such as a goniometer, to determine range of motion, and statistically valid questionnaires measuring mood, stress, concentration, and patience. Two questionnaires that would have been helpful for measuring mood and stress are the State Trait Anxiety Inventory (STAI, 20) and the Profile of Mood States (POMS, 23) ${ }^{(22,39)}$. Also, the only measure for concentration and patience in this report was the client's comments. A more reliable and valid measure such as the UK World Health Organization generic measure of quality of life (WHOQOL-100) ${ }^{(40)}$ would have been valuable. Also, during postural observation, rather than using the terms, "mild, moderate or severe", more quantifiable measurements should have been used, such as measuring with a ruler. Similar to this, during resisted range of motion, rather than using the terms "weak, normal, or strong", more quantifiable measurements should have been used, such as Magee's muscle test grading from $0-5^{(36)}$. Had the author been aware of the benefits of these measurement tools prior to the commencement of the treatment series, these would have been implemented, and they are encouraged for future use.

\section{Smoking and Diet}

One complicating factor was that the client made some lifestyle changes around the same time as the onset of the treatment series. Seven days before the first assessment, the client quit smoking. The client and the author thought that her stress levels would increase, and in turn her pain levels, because the client claimed smoking was her stress reliever. However, it was discovered that quitting seemed to have a positive effect on her symptoms and she was able to find other stress outlets, such as exercising. Although it is hypothetical, there is the possibility that the massage therapy intervention assisted in the client's effort to stop smoking. Some small-scale studies are in support of this theory; however, many more studies are needed ${ }^{(39,41)}$.

After the treatment series concluded and the author further examined the daily journal entries, additional information was revealed that may necessitate a recommendation for the client to see a nutritionist. Over the course of 57 days, 31 meals were skipped, mostly breakfast and lunch. Also, caffeinated beverages (mostly coffee) were consumed on 39 days and alcoholic beverages (mostly red wine and beer) were consumed on 27 days. This may have been contributing to the symptoms of TMD because omitting meals leads to poor nutrient intake ${ }^{(42)}$ which could affect mental, physical, and emotional well-being. The client's caffeine intake also may have been contributing to her symptoms because it stimulates muscles to contract and, therefore, become more tense ${ }^{(7)}$. Excessive alcohol intake has various adverse effects on the body and on rare occasions, can cause skeletal muscle conditions $^{(43)}$. Perhaps a nutritionist could help with these concerns, as recommendations regarding diet are generally out of the scope of practice for massage therapists.

\section{Recommendations for Future Studies}

Considering the above discussion on smoking cessation and diet, it would be intriguing to see more studies on the relationships between smoking cessation, diet, massage therapy, TMD and/or stress. Also, due to the controversies regarding the biochemical mechanism of massage on stress reduction, further research is warranted. Another beneficial direction for research would be to determine the effectiveness of intra-oral massage, considering the author was unable to locate any articles regarding the effectiveness of this type of treatment on TMD. A highly recommended resource to use for future studies on intra-oral massage protocol is DeLany ${ }^{(26)}$. Although 
there are research advantages to following detailed protocols, as in this case report, it may be unrealistic to do so considering that massage therapists in clinical practice often provide individualized treatment plans that may vary from protocol, if appropriate. Similarly, although applying a diversity of techniques may have been the best option for this report, it does not allow one technique to be singled out as most effective. Future case reports using only one intervention could produce interesting results; however, clients may not see large improvements because this deviates from the holistic approach.

\section{CONCLUSION}

In conclusion, if the results of this case report were to be supported by more rigorous study, massage therapy could prove to be an effective treatment to increase range of motion, decrease pain and stress, and reduce hypertonicity associated with TMD.

\section{ACKNOWLEDGEMENTS}

Melissa would like to extend a special thank you to her case report supervisor, James MacIntyre DC, and her clinical supervisor, Chandra Kastern MT. Additionally, gratitude is expressed to Jordan Pierson for being encouraging throughout the process of compiling this report. Heartfelt appreciation is offered to the Massage Therapy Foundation which recognized this report with a silver place award for the Student Case Report Contest in 2010.

\section{CONFLICT OF INTEREST NOTIFICATION}

The author declares that there are no conflicts of interest.

\section{COPYRIGHT}

Published under the CreativeCommons AttributionNonCommercial-NoDerivs 3.0 License.

\section{REFERENCES}

1. Epker J, Gatchel RJ, Ellis E. A model for predicting chronic TMD: Practical application in clinical settings. J Am Dent Assoc. 1999;130(10):1470-1475.

2. Biel A. Trail guide to the body: How to locate muscles, bones and more, 3rd ed. Boulder, CO: Books of Discovery; 2005.

3. Jerjes W, Upile T, Abbas S, et al. Muscle disorders and dentition-related aspects in temporomandibular disorders: Controversies in the most commonly used treatment modalities. Int Arch Med. 2008;1(23).
4. Rattray F and Ludwig L. Clinical massage therapy: Understanding, assessing and treating over 70 conditions. Elora, Ontario: Talus; 2000.

5. McNeely ML, Olivo SA, Magee DJ. A systematic review of the effectiveness of physical therapy interventions for temporomandibular disorders. Phys Ther. 2006;86(5):710-725.

6. Macfarlane TV, Blinkhorn AS, Davies RM, et al. Predictors of outcome for orofacial pain in the general population: A fouryear follow-up study. J Dent Res. 2004;83(9):712-717.

7. Wright EF and Schiffman EL. Treatment alternatives for patients with masticatory myofascial pain. J Am Dent Assoc. 1995;126(7):1030-1039.

8. Conti P, Santos C, Kogawa E, et al. The treatment of painful temporomandibular joint clicking with oral splints: A randomized clinical trial. J Am Dent Assoc. 2006;137(8):1108-1114.

9. Reychler $\mathrm{H}$ and Tovaru S. Current recommendations for the diagnosis of temporo-mandibular joint disorders - Review paper part two. Mcedica J Clin Med. 2008;3(2):130-135.

10. Christensen GJ, Abnormal occlusal conditions: a forgotten part of dentistry. J Am Dent Assoc. 1995;126(12):1667-1668.

11. Gottlieb RJ and Lautar CJ. Temporomandibular joint dysfunction revisited: comprehensive treatment options. Access. 2001;15(5):48-54.

12. Capellini VK, Souza GS, Faria CR. Massage therapy in the management of myogenic TMD: A pilot study. J Appl Oral Sci. 2006;14(1):21-26.

13. De Laat A, Stappaerts K, Papy S. Counseling and physical therapy as treatment for myofascial pain of the masticatory system. J Orofac Pain. 2003;17(1):42-49.

14. Vernon $\mathrm{H}$ and Humphreys BK. Chronic mechanical neck pain in adults treated by manual therapy: A systematic review of changed scores in randomized controlled trials of a single session. J Man Manip Ther. 2008;16(2):42-52.

15. Eisensmith, LP. Massage therapy decreases frequency and intensity of symptoms related to temporomandibular joint syndrome in one case study. J Bodyw Mov Ther. 2007;11(3):223-230.

16. Medlicott MS and Harris SR. A systematic review of the effectiveness of exercise, manual therapy, electrotherapy, relaxation training, and biofeedback in the management of temporomandibular disorder. J Am Phys Ther Assoc. 2006;86(7):955-973.

17. Schneider J, Vuckovic N, DeBar L. Willingness to participate in complementary and alternative medicine clinical trials among patients with craniofacial disorders. J Altern Complement Med. 2004;9(3):389-401.

18. DeBar L, Vuckovic N, Scheider J, et al. Use of complementary and alternative medicine for temporomandibular disorders. $J$ Orofac Pain. 2003;17(3):224-236.

19. Rich G. Massage therapy: Significance and relevance to professional practice. Prof Psychol Res Pr. 2010;41(4):325-332.

20. Kemper KJ and Shannon S. CAM therapies to promote healthy moods. Pediatr Clin North Am. 2007;54(6):901-926.

21. Field T, Hernandez-Reif M, Diego M, et al. Cortisol decreases and serotonin and dopamine increase following massage therapy. Int J Neurosci. 2005;115(10):1397-1413.

22. Bost $\mathrm{N}$ and Wallis $\mathrm{M}$. The effectiveness of a 15 minute weekly massage in reducing physical and psychological stress in nurses. Aust J Adv Nurs. 2006;23(4):28-33. 


\section{PIERSON: CHANGES IN TEMPOROMANDIBULAR JOINT DYSFUNCTION SYMPTOMS}

23. Suresh S, Wang S, Porfyris S, et al. Massage therapy in outpatient pediatric chronic pain patients: Do they facilitate significant reductions in levels of distress, pain, tension, discomfort, and mood alterations? Paediatr Anaesth. 2008;18(9):884-887.

24. Moyer C, Seefeldt L, Mann E, et al. Does massage therapy reduce cortisol? A comprehensive quantitative review. $J$ Bodyw Mov Ther. 2011;15(1):3-14.

25. Listing M, Krohn M, Liezmann C, et al. The efficacy of classical massage on stress perception and cortisol following primary treatment of breast cancer. Arch Women's Ment Health. 2010;13(2):165-173.

26. DeLany J. Temporomandibular dysfunction: neuromuscular therapy. J Bodyw Mov Ther. 1997;1(4):199-203.

27. Hammer W. Integrative fascial release \& functional testing. Australas Chiropr Osteopathy. 2000;9(1):13-16.

28. Simons D, Travell J, Simons L. Travell \& Simons 'myofascial pain and dysfunction: the trigger point manual. Vol. 1:Upper half of body, 2nd ed. Baltimore, MD: Williams and Wilkins; 1999.

29. Maddocks-Jennings W and Wilkinson J. Aromatherapy practice in nursing: literature review. J Adv Nurs. 2004;48(1):93-103.

30. Heuberger E, Hongratanaworakit T, Böhm C, et al. Effects of chiral fragrances on human autonomic nervous system parameters and self-evaluation. Chem Senses. 2001;26(3):281-292.

31. Valnet J. The practice of aromatherapy: A classic compendium of plant medicines \& their healing properties. Rochester, VT; Healing Arts Press: 1990.

32. Brown DW. Teach yourself aromatherapy. Chicago IL: Contemporary Books; 2003.

33. Kaushik R, Kaushik RM, Mahajan SK, et al. Biofeedback assisted diaphragmatic breathing and systemic relaxation versus propranolol in long term prophylaxis of migraine. Complement Ther Med. 2005;13(3):165-174.
34. Robinson N, Donaldson J, Lorenc A. Shiatsu: A review of the evidence [Internet]. London, UK: Thames Valley University; 2006 [cited 2010 Sept 1]. Available from: http://www.shiatsusociety. org/sites/default/files/Shiatsu\%20Systematic\%20Evidence $\% 20$ Review\%20Complete.pdf

35. Kisner $\mathrm{C}$ and Colby LA. Therapeutic exercise; foundations and techniques, 5th ed. Philadelphia, PA: F. A. Davis Company; 2007.

36. Magee D. Orthopedic physical assessment, 5th ed. St. Louis, MO: Saunders Elsevier; 2008.

37. Uyanik J and Murphy E. Evaluation and management of TMDs, part 1: History, epidemiology, classification, anatomy, and patient evaluation. Dent Today. 2003;22(10):140-145.

38. Nickel W. Issues in clinical massage: documenting progress. Massage Therapy J. 1993;32(3):45.

39. Hernandez-Reif M, Field T, Hart S. Smoking cravings are reduced by self-massage. Prev Med. 1999;28(1):28-32.

40. Mason V, Skevington S, Osborn M. Development of a pain and discomfort module for use with the WHOQOL-100. Qual Life Res. 2004;13(6):1138-1152.

41. Sood A, Ebbert J, Sood R, et al. Complementary treatments for tobacco cessation: A survey. Nicotine Tob Res. 2006;8(6):767-771.

42. Sjöberg A, Hallberg L, Höglund D, et al. Meal pattern, food choice, nutrient intake and lifestyle factors in the Göteborg Adolescence Study. Eur J Clin Nutr. 2003;57:1569-1578.

43. Preedy V, Adachi J, Ueno Y, et al. Alcoholic skeletal myopathy: definitions, features, contribution of neuropathy, impact and diagnosis. Eur J Neurol. 2001;8(6):677-687.

Corresponding author: Melissa Joan Pierson, MT, private practice and Optimum Wellness Centres, C-1B, 901 - 64 Ave NE, Calgary, Alberta, Canada, T2E 7P4

E-mail: melissajoan6@yahoo.com 